\title{
The Hybrid Light Source for Projection Display
}

\author{
Qingying Deng1,2, Hua Chen ${ }^{2}$, Guohui Li' ${ }^{1}$, Jianquan Yao ${ }^{1}$ \\ ${ }^{1}$ Tianjin University, TEDA or King Hi-Tech CO. LTD., Tianjin, China \\ ${ }^{2}$ Beijing Moreget Creative Technology CO. LTD., Beijing, China \\ Email: moreget_d@chinamoreget.com
}

Received 21 November 2015; accepted23 August 2016; published 30 August 2016

\begin{abstract}
A scheme of hybrid light source using lasers and LEDs for projection display is presented; the simulation results show that projectors with the proposed scheme can achieve high brightness of over $1000 \mathrm{~lm}$, good uniformity of illumination and chromaticity. It also provides an improved method for light source with longer life, wider color garment and higher adaptability to environment which can replace UHP in traditional projectors.
\end{abstract}

Keywords

Light Source in UHP, Laser, LED

\section{Introduction}

Lasers and LEDs, as two types of new light sources, have been used in projection area for years [1]-[3]. Lasers are generally used in the area of micro-projection and large movie theatres projection, for its high brightness, good directivity, long life time, environmentally friendly and energy saving characteristics [4] [5]. Despite the above advantages, it is still far more expensive than conventional light sources, which prevents a wide range of its applications. LEDs are more widely used than lasers in projectors for its low cost as we all know [6] [7]. But its low brightness, especially for green LEDs, prevents it being used in mainstream commercial projectors. In order to overcome the above shortcomings, a new kind of light source composed of lasers, LEDs and phosphor powder, has been proposed and commercialized [8]. In this method, green colors are generated by ways that blue lasers stimulate the phosphor. In this paper, we propose a novel hybrid light source scheme, in which green lights are composed of green lasers and green LEDs, in the way that the brightness of green color is substantially increased by green lasers. The simulation results show that projectors with the proposed scheme can achieve high brightness of over $1000 \mathrm{~lm}$, good uniformity of illumination and chromaticity.

\section{Comparison between the Light Sources}

The main parameters of hybrid light source (composed of lasers, LEDs and phosphor powder), pure Lasers and pure LEDs are listed in Table 1, which depicts their differences. 
Table 1. Comparison between the new light sources

\begin{tabular}{|c|c|c|c|c|c|}
\hline Туре & Color & Efficiency & Flux from the projector & Color garment & Life \\
\hline \multirow{3}{*}{ LEDs } & R (Luminus) & $\sim 7 \%-8 \%$ & \multirow{3}{*}{$10-500 \mathrm{~lm}$} & \multirow{3}{*}{$105 \%$} & \multirow{3}{*}{$\sim 20,000 \mathrm{hr}$} \\
\hline & G (Luminus) & $\sim 4 \%$ & & & \\
\hline & B (Luminus) & $\sim 8 \%-10 \%$ & & & \\
\hline \multirow{3}{*}{ Lasers } & R (Mitsubishi) & $\sim 40 \%$ & \multirow{3}{*}{$10-20,000 \operatorname{lm}$} & \multirow{3}{*}{$\sim 200 \%$} & \multirow{3}{*}{$10,000-20,000 \mathrm{hl}$} \\
\hline & G (PHOEV) & $20 \%$ & & & \\
\hline & B (Nichia) & $20 \%$ & & & \\
\hline \multirow{3}{*}{ Hybrid } & R (Luminus) & $\sim 7 \%-8 \%$ & \multirow{3}{*}{$1000-3000 \operatorname{lm}$} & \multirow{3}{*}{$\sim 80 \%$} & \multirow{3}{*}{$10,000-20,000 \mathrm{hr}$} \\
\hline & G (phosphor) & $\sim 14 \%$ & & & \\
\hline & B (Nichia) & $20 \%$ & & & \\
\hline
\end{tabular}

\section{Lens Design and Analysis}

\subsection{Principles of Etendue}

In conventional LED projection design, it is of particular importance to pay attention to the Etendue of the LED and that it is properly matched to that of the system.

For rotationally-symmetric optical systems with half aperture angle $\alpha$ :

$$
E=n^{2} \cdot \pi \cdot \sin ^{2}(\alpha) \cdot A
$$

For 0.7" imager with acceptance angle of $\pm 12^{\circ}$ and aspect ratio of $4: 3, \mathrm{E}_{\text {system }}=16.16 \mathrm{~mm}^{2}$, for a fiber coupled laser, if the diameter of the fiber is $0.4 \mathrm{~mm}, \mathrm{NA}=0.22$, then $\mathrm{E}_{\text {laser }}=0.019 \mathrm{~mm}^{2}$, for LEDs, if we choose PT54 as the light source, then $\mathrm{E}_{\mathrm{LED}}=16.96 \mathrm{~mm}^{2}$.

We can see that $E_{\text {laser }}$ can almost be ignored compared to $E_{\mathrm{LED}}$, but we can achieve power of more than $6 \mathrm{~W}$,

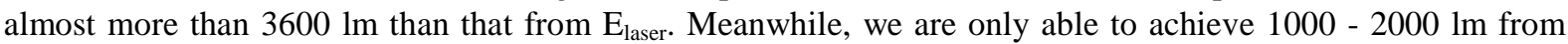
$E_{L E D}$. So it is possible for us to obtain such light source which is more than 4600 - $5600 \mathrm{~lm}$ with Etendue below $17 \mathrm{~mm}^{2}$, which is almost the same as $\mathrm{E}_{\text {system }}$.

\subsection{Optical Structure of the Hybrid Light Source}

RGB light from LEDs is collimated by micro objective, then overlapped by an X-plate, focused into integration rod. Decoherenced green Lasers are imported from the pinhole in the reflector plate, as depicted in Figure 1. Both Lasers and LEDs have the same optical axis. Unlike conventional design, field lens are added at the focal plane, which is near the entrance of the integration rod, as depicted in Figure 2. Because the field lens are at the position of the image place of LEDs, so they have a very small impact on the features of the image such as size, angle and Etendue.

As regard to lasers, field lens are not at the position of their focus place. Decoherenced green lasers are collimated by focusing lens and focused by field lens to a specified cone angle, which is helpful for good uniformity of illumination and chromaticity. Although lasers and LEDs do not have the same focal plane, Lasers have much narrower beam width which makes it easy to get into the integration rod without loss.

\subsection{Green Lasers}

Green lasers from fibers are decoherenced by a diffuser, the decoherenced lasers are imaged into the position where a pinhole is placed, as depicted in Figure 3. Careful design of the diameter and the location of the pinhole in the optical system are needed, to meet the following requirements:

1) The degree of the decoherence of the green lasers.

The more decoherence of the green lasers, the more increased the amount of Etendue of the green lasers, which will enlarge the diameter of the pinhole to prevent the lasers from blocking, while at the same time more light from green LEDs will escape from the pinhole. So we should make the balance. 


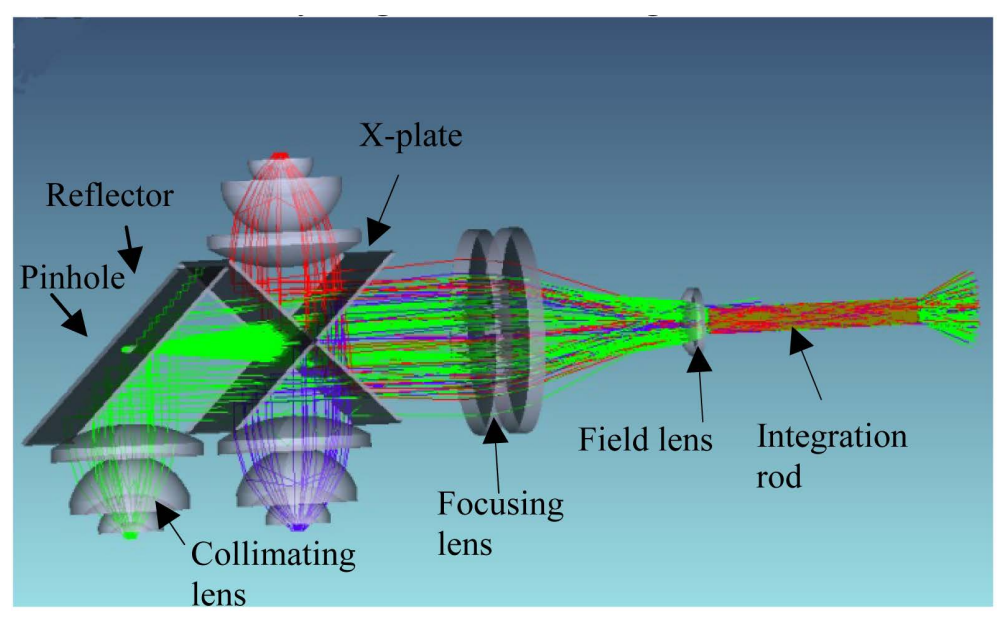

Figure 1. Optical structure of the hybrid light source.

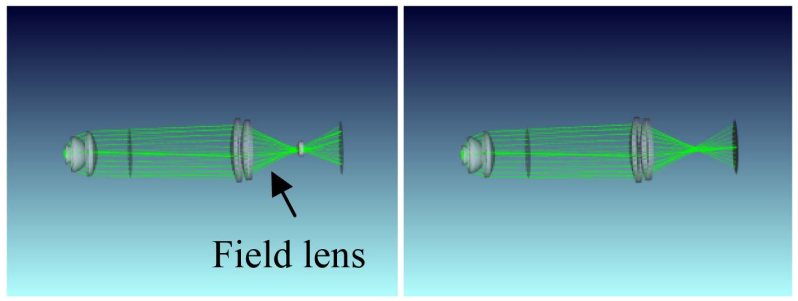

Figure 2. New design and conventional design.

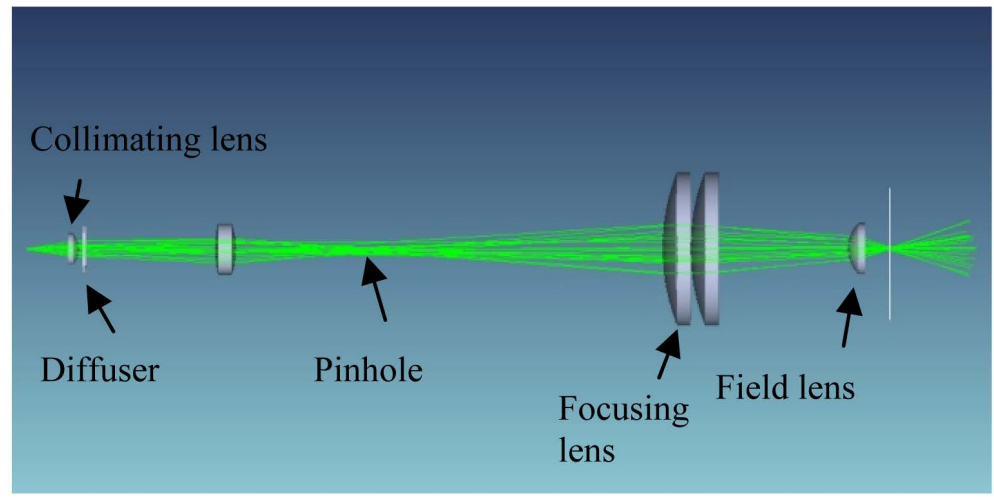

Figure 3. Optical path of decoherenced green lasers

2) The specified cone angle for illumination and coaxial features of LEDs and Lasers.

The high power, small size and commercialized green lasers provided by Phoebus vision are demonstrated in Figure 4. More than $6 \mathrm{~W}$ green lasers are outputted from a very compact volume, which can be integrated into hybrid light source with LEDs, through the method mentioned above, to help projectors with over $1000 \mathrm{~lm}$ output.

\section{Simulation}

In the simulation, we put six detectors at the exit of the integration rod, each detector can obtain illumination information and color coordinates. The simulation results show that a good color uniformity of $\Delta x^{\prime} y^{\prime}<0.01$ and a good illumination uniformity of $>90 \%$ can be achieved (Figure 5).

We find in the simulation that the coaxial performance between lasers and LEDs is of particular importance to the uniformity of illumination and chromaticity. 


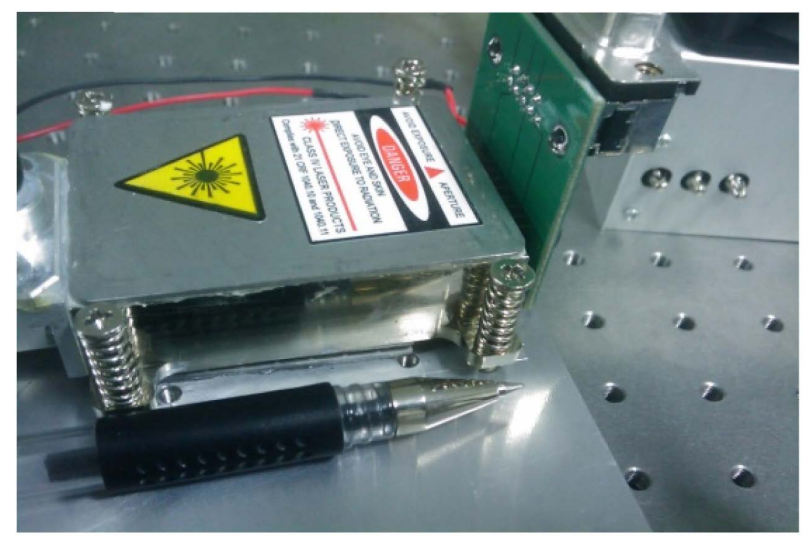

Figure 4. Green lasers
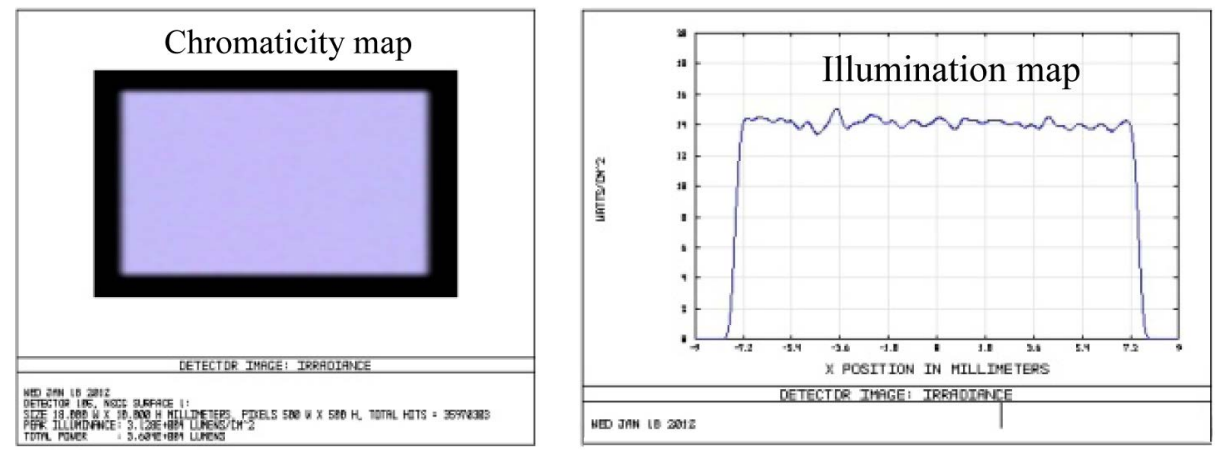

Figure 5. The simulation of illumination and chromaticity map.

\section{Conclusion}

A scheme of hybrid light source composed of lasers and LEDs for projection display is presented; the simulation results show that projectors with high brightness of more than $1000 \mathrm{~lm}$, good uniformity of illumination and chromaticity can be achieved. It can be used as a new kind of projection light source with high cost-performance.

\section{References}

[1] Jansen, M., et al. (2007) Visible Laser Sources for Projection Displays. Proc. SPIE, 6489, 648908-1-648908-6. http://dx.doi.org/10.1117/12.716285

[2] Wu, R.-M., Tu, D.-W. and Huang, Z.-H. (2009) Design of Uniform Illumination Projector with High Power LED. Journal of Applied Optics, No. 3.

[3] Xu, D.-S., Chen, X., Zhu, X. and Zheng, L.-H. (2014) A Dimming Lighting Source Baser on Cold and Warm White LEDs. Acta Optica Sinica, 34.

[4] Zheng, G., et al. (2008) Laser Digital Cinema Projector. Journal of Display Technology, 4, 314-318. http://dx.doi.org/10.1109/JDT.2008.924163

[5] Yan, B.X., et al. (2011) Green Laser for Laser Display. ASID’2011 Digest, 170-173.

[6] Feng, Q.-B., Niu, H.-L., Hua, Y.-K. and L, G.-Q. (2011) LED-Based Illumination System for Solid-State Volumetric True 3D Display. Opto-Electronic Engineering, No. 9.

[7] Feng, Q.-B., Yang, G.-L., Jing, C.-L. and L, G.-Q. (2014) LED-Based Projection Light Source for Solid-State Volumetric True-3D Display. Optics and Precision Engineering, No. 5.

[8] Advantages of Hybrid Light Source-Laser+ LED. http://m.laser.ofweek.com/2014-09/ART-240002-11000-28883075.html 


\section{Submit or recommend next manuscript to SCIRP and we will provide best service for you:}

Accepting pre-submission inquiries through Email, Facebook, LinkedIn, Twitter, etc.

A wide selection of journals (inclusive of 9 subjects, more than 200 journals)

Providing 24-hour high-quality service

User-friendly online submission system

Fair and swift peer-review system

Efficient typesetting and proofreading procedure

Display of the result of downloads and visits, as well as the number of cited articles

Maximum dissemination of your research work

Submit your manuscript at: http://papersubmission.scirp.org/ 